\title{
Density Functional Theory Study of Nitrous Oxide Decomposition over Fe- and Co-ZSM-5
}

\author{
Jason A. Ryder ${ }^{4}$, Arup K. Chakraborty ${ }^{2,3,4}$, Alexis T. Bell ${ }^{1,4}$ \\ Chemical $^{1}$ and Materials ${ }^{2}$ Sciences Divisions \\ Lawrence Berkeley National Laboratory \\ and \\ Departments of Chemistry ${ }^{3}$ and Chemical Engineering ${ }^{4}$ \\ University of California \\ Berkeley, CA 94720-1462
}

\author{
Submitted to \\ Journal of Physical Chemistry
}

December 19, 2001 


\begin{abstract}
Iron- and cobalt-exchanged ZSM-5 are active catalysts for the dissociation of nitrous oxide. In this study, density functional theory was used to assess a possible reaction pathway for the catalytic dissociation of $\mathrm{N}_{2} \mathrm{O}$. The active center was taken to be mononuclear $[\mathrm{FeO}]^{+}$or $[\mathrm{CoO}]^{+}$, and the surrounding portion of the zeolite was represented by a 24-atom cluster. The first step of $\mathrm{N}_{2} \mathrm{O}$ decomposition involves the formation of $\left[\mathrm{FeO}_{2}\right]^{+}$or $\left[\mathrm{CoO}_{2}\right]^{+}$and the release of $\mathrm{N}_{2}$. The metal-oxo species produced in this step then reacts with $\mathrm{N}_{2} \mathrm{O}$ again, to release $\mathrm{N}_{2}$ and $\mathrm{O}_{2}$. The apparent activation energies for $\mathrm{N}_{2} \mathrm{O}$ dissociation in Fe-ZSM-5 and Co-ZSM-5 are 39.4 and $34.6 \mathrm{kcal} / \mathrm{mol}$, respectively. The preexponential factor for the apparent first-order rate coefficient is estimated to be of the order $10^{7} \mathrm{~s}^{-1} \mathrm{~Pa}^{-1}$. While the calculated activation energy for $\mathrm{Fe}-$ ZSM-5 is in good agreement with that measured experimentally, the value of the preexponential factor is an order of magnitude smaller than that observed. The calculated activation energy for Co-ZSM-5 is higher than that reported experimentally. However, consistent with experiment, the rate of $\mathrm{N}_{2} \mathrm{O}$ decomposition on Co-ZSM-5 is predicted to be significantly higher than that on Fe-ZSM-5.
\end{abstract}




\section{Introduction}

Transition metals cation-exchanged into ZSM-5 have been shown to catalyze the dissociation of nitrous oxide to oxygen and nitrogen. ${ }^{1-7}$ The activity of such catalysts depends on the identity of the exchanged transition metal cation and decreases in the order $\mathrm{Rh}, \mathrm{Ru}>\mathrm{Pd}>\mathrm{Cu}>\mathrm{Co}>\mathrm{Fe}>\mathrm{Pt}>\mathrm{Ni}>\mathrm{Mn}^{1-3}$ Studies of nitrous oxide dissociation over $\mathrm{Cu}-$, Co-, and Fe-ZSM-5 show that the reaction is first order in $\mathrm{N}_{2} \mathrm{O}$ and in the case of Cu-ZSM-5 is inhibited by $\mathrm{O}_{2}{ }^{1,}, 5,6,8$ It has also been reported that isotopically labeled oxygen scrambles into the products of nitrous oxide dissociation in the case of Cu-ZSM-5 but not in the case of either Co- or Fe-ZSM-5. This suggests that the mechanisms of $\mathrm{N}_{2} \mathrm{O}$ dissociation are similar on Co- and Fe-ZSM-5, and that the mechanism for $\mathrm{Cu}-\mathrm{ZSM}-5$ may be different.

Much effort has been devoted to the characterization of Fe in Fe-ZSM-5. ${ }^{9-19}$ Work by Lobree et al. suggests that up to a Fe/Al ratio of $0.56, \mathrm{Fe}^{3+}$ cations substitute, as $\left[\mathrm{Fe}(\mathrm{OH})_{2}\right]^{+}$, on a one for one basis with Brønsted acid protons. ${ }^{9}$ Similar conclusions have been reported by Sachtler and co-workers.$^{10}$ However, other authors have demonstrated that iron may be present as binuclear oxo cations and as small particles of iron oxide. ${ }^{11-15}$ The extent to which iron cations can exchange as such species has been estimated by Rice et al. ${ }^{16}$ These authors showed that for a $\mathrm{Si} / \mathrm{Al}$ ratio of 25 if all pairs of cation exchange sites capable of accommodating species such as $[\mathrm{Fe}(\mathrm{OH}) \mathrm{OFe}(\mathrm{OH})]^{2+}$ were filled, the corresponding value of Fe/Al would be 0.50 , assuming that the distance between $\mathrm{Al}$ atoms in the cation-exchange sites is $<7.5 \AA$. As the $\mathrm{Si} / \mathrm{Al}$ ratio increases the value of Fe/Al rapidly decreases. Similar conclusions about the accommodation of oxo metal cations have been reported by Goodman et al. ${ }^{17,18} \mathrm{Fe}^{3+}$ cations can also be 
accommodated as $[\mathrm{Fe}(\mathrm{OH})]^{2+}$ in five- and six-membered rings containing two $\mathrm{Al}$ atoms. For such species the value of $\mathrm{Fe} / \mathrm{Al}$ is 0.07 if the $\mathrm{Si} / \mathrm{Al}$ ratio of the zeolite is 25 . Here too, the value of $\mathrm{Fe} / \mathrm{Al}$ decreases with increasing $\mathrm{Si} / \mathrm{Al}$ ratio. By contrast, there are no constraints on the $\mathrm{Fe} / \mathrm{Al}$ ratio for cations such as $\left[\mathrm{Fe}(\mathrm{OH})_{2}\right]^{+}$or $[\mathrm{FeO}]^{+}$, since only isolated charge-exchange sites are require to accommodate these species. Thus, it is reasonable to conclude that a significant fraction of the $\mathrm{Fe}^{3+}$ cations exchanged into ZSM-5 ( $\mathrm{Si} / \mathrm{Al} \geq 25)$ would be present as isolated cations associated with a single chargeexchange site. It is also notable that in the case of Co-ZSM-5, an even more active catalyst to $\mathrm{N}_{2} \mathrm{O}$ decomposition than Fe-ZSM-5, there is no evidence for binuclear Co species. $^{20}$

Attempts to characterize the energetics of $\mathrm{N}_{2} \mathrm{O}$ decomposition on Fe-ZSM-5 via quantum chemical calculations have been reported by several author. ${ }^{21-24}$ Yoshizawa et al. have proposed a model for the dissociation of nitrous oxide in Fe-ZSM-5 based on an isolated 3T-atom zeolite model. ${ }^{21,22}$ While they demonstrate that $\mathrm{N}_{2} \mathrm{O}$ decomposition could occur on such a site, their proposed reaction mechanism assumes that $\mathrm{O}_{2}$ desorbs via the process, $\mathrm{Z}^{-}\left[\mathrm{Fe}(\mathrm{O})_{2}\right]^{+} \rightarrow \mathrm{Z}^{-} \mathrm{Fe}^{+}+\mathrm{O}_{2}(\mathrm{~g})$. This step seems unrealistic, since the experimental evidence does not support the existence of $\mathrm{Fe}^{+}$cations in ZSM-5.,19 Yakovlev and coworkers have also carried out quantum calculations of $\mathrm{N}_{2} \mathrm{O}$ decomposition. In the first of their studies, the active sites was modeled as $\mathrm{M}(\mathrm{OH})_{3}\left(\mathrm{H}_{2} \mathrm{O}\right)_{2}(\mathrm{M}=\mathrm{Fe}, \mathrm{Co}, \mathrm{Rh}){ }^{23}$ The energies of intermediates and transition states were computed and it was determined that $\mathrm{Co}$ and $\mathrm{Rh}$ sites are more active than $\mathrm{Fe}$. In the second study, the energetics of $\mathrm{N}_{2} \mathrm{O}$ decomposition were investigated for binuclear $\mathrm{Fe}$ complexes in Fe-ZSM-5. ${ }^{24}$ The zeolite was modeled by a pair of $5 \mathrm{~T}$ rings sharing an 
edge and the Fe complex was represented as either $[(\mathrm{HO}) \mathrm{FeOFe}(\mathrm{OH})]^{2+}$ or $[\mathrm{FeOFe}]^{2+}$. While only stable states for active sites and intermediates along the reaction path were considered, the authors did show that oxo-metal cations could serve as active sites for $\mathrm{N}_{2} \mathrm{O}$ decomposition.

In this study, we report an investigation of the mechanisms of nitrous oxide dissociation in Co- and Fe-ZSM-5 using density functional theory. We proceed by postulating a mechanism for the dissociation process, computing the energetics for each elementary step, and developing a rate expression for the overall rate of reaction. The apparent rate parameters (activation energy and preexponential factor) are then compared with experiments to evaluate the plausibility of the proposed mechanism.

\section{Theoretical Methods}

The catalytically active center and a portion of the zeolite framework are represented by a 24-atom cluster. As shown in Figure 1, the portion of the cluster describing the zeolite contains an $\mathrm{Al}$ atom in the $\mathrm{T} 12$ site of the framework surrounded by shells of $\mathrm{O}$ and $\mathrm{Si}$ atoms. The terminal $\mathrm{Si}$-atoms are fixed in their crystallographic positions as reported by Olson et al. ${ }^{25}$ Dangling bonds are terminated by $\mathrm{H}$-atoms located $1.5 \AA$ from each terminal Si atom oriented in the direction of the next T (tetrahedral) site. The anionic cluster is charge-compensated by a metal-oxo species, $[\mathrm{FeO}]^{+}$or $[\mathrm{CoO}]^{+}$, placed between two of the four $\mathrm{O}$ atoms surrounding the $\mathrm{Al}$ atom.

The choice of $[\mathrm{FeO}]^{+}$or $[\mathrm{CoO}]^{+}$as the active center is guided by the following experimental observations. ${ }^{9}$ Dry exchange of $\mathrm{H}-\mathrm{ZSM}-5$ with $\mathrm{FeCl}_{3}$ results in the release of $\mathrm{HCl}$ and the replacement of each Bronsted acid proton by $\left[\mathrm{FeCl}_{2}\right]^{+}$. The $\mathrm{Cl}$ atoms 
associated with iron are removed by washing in water, with the results that the chargeexchange positions in Fe-ZSM-5 are now occupied by $\left[\mathrm{Fe}(\mathrm{OH})_{2}\right]^{+}$. Upon heating, the water is liberated and the charge compensating unit becomes $[\mathrm{FeO}]^{+}$. As noted in the Introduction, $\left[\mathrm{Fe}(\mathrm{OH})_{2}\right]^{+}$and $[\mathrm{FeO}]^{+}$are expected to be the predominant forms of in which $\mathrm{Fe}^{3+}$ cations are present in $\mathrm{ZSM}-5$ with $\mathrm{Si} / \mathrm{Al}$ ratio of 25 or greater.

Quantum chemical calculations of the geometry and energies of ground states and transition-state structures were performed using non-local, gradient-corrected densityfunctional theory (DFT). ${ }^{26}$ To represent the effects of exchange and correlation, Becke's 3-parameter exchange with correlation functionals of Lee, Yang, and Parr (B3LYP) were used. $^{27,28}$ Basis sets at the $6-31 \mathrm{G}$ or double-zeta level were used for all atoms, with the exception of Fe. To describe Fe, the energy-consistent pseudopotentials of Stuttgart and Bonn were used in the small-core approximation. ${ }^{29}$ Polarization functions were added to all atoms, with the exception of terminal H groups. No corrections were made for basisset superposition error. All calculations were carried out using the Jaguar 4.0 suite of programs (Schrödinger, Inc.) and Gaussian 98..$^{30,31}$ During these calculations all atoms of the cluster were allowed to relax with the exception of the terminal $\mathrm{Si}$ atoms, as noted above.

Overall equilibrium constants and reaction rate constants were computed using standard statistical mechanics and absolute rate theory. ${ }^{32}$ We use the harmonic approximation, and include contributions of the translational, rotational, and vibrational partition functions of all gaseous species participating in the reaction and the vibrational contribution due to the zeolite cluster. Since the zeolite cluster is part of a solid, translational and rotational partition functions for the zeolite were assumed to be equal in 
the reactant and transition-state. All molecular structures were assumed to be in the ground-state electronic configuration.

\section{Results and Discussion}

The dissociation of $\mathrm{N}_{2} \mathrm{O}$ at a single metal center can be envisioned to proceed via the following sequence of steps:

$$
\begin{gathered}
\mathrm{N}_{2} \mathrm{O}(\mathrm{g})+\mathrm{Z}^{-}[\mathrm{MO}]^{+} \rightleftharpoons \mathrm{Z}^{-}\left[\mathrm{MO}\left(\mathrm{N}_{2} \mathrm{O}\right)\right]^{+} \\
\mathrm{Z}^{-}\left[\mathrm{MO}\left(\mathrm{N}_{2} \mathrm{O}\right)\right]^{+} \rightarrow \mathrm{N}_{2}(\mathrm{~g})+\mathrm{Z}^{-}\left[\mathrm{M}(\mathrm{O})_{2}\right]^{+} \\
\mathrm{N}_{2} \mathrm{O}(\mathrm{g})+\mathrm{Z}^{-}\left[\mathrm{M}(\mathrm{O})_{2}\right]^{+} \rightleftharpoons \mathrm{Z}^{-}\left[\mathrm{M}(\mathrm{O})_{2}\left(\mathrm{~N}_{2} \mathrm{O}\right)\right]^{+} \\
\mathrm{Z}-\left[\mathrm{M}(\mathrm{O})_{2}\left(\mathrm{~N}_{2} \mathrm{O}\right)\right]^{+} \rightarrow \mathrm{N}_{2}(\mathrm{~g})+\mathrm{Z}^{-}\left[\mathrm{MO}(\mathrm{O})_{2}\right]^{+} \\
\mathrm{Z}^{-}\left[\mathrm{M}(\mathrm{O})_{3}\right]^{+} \rightleftharpoons \mathrm{O}_{2}(\mathrm{~g})+\mathrm{Z}^{-}[\mathrm{MO}]^{+}
\end{gathered}
$$

In this sequence, $\mathrm{M}$ represents either Fe or Co. Reactions 1 and 3 involve the adsorption of gas-phase $\mathrm{N}_{2} \mathrm{O}$, assumed to be reversible, to the catalytically active site. Reactions 2 and 4 describe the dissociation of each of the adsorbed $\mathrm{N}_{2} \mathrm{O}$ species to give two equivalents of gas-phase $\mathrm{N}_{2}$ and two surface oxygen species. Reaction 5 represents the desorption of $\mathrm{O}_{2}$ molecule, which is also assumed to be reversible. The sum of these five steps constitutes a complete catalytic cycle. In what follows we present the calculations on the energetics for Reactions 1 and 2 first, and then Reactions 3 and 4. The desorption of $\mathrm{O}_{2}$ via Reaction 5 is examined separately, as well as the possibility of desorbing $\mathrm{O}_{2}$ from $\mathrm{Z}^{-}\left[\mathrm{M}(\mathrm{O})_{2}\right]^{+}$. It should be noted that while the proposed mechanism leads to a rate expression that is consistent with experimental observations, other mechanisms are also possible. 
Figure 1 shows the calculated energy profile for Reactions 1 and 2 occurring over Fe-ZSM-5. The corresponding calculations for Co-ZSM-5 are shown in Figure 2. In both figures, structures $1(\mathrm{a}), 1(\mathrm{~b})$ and 1(d) correspond to local minima on the potential energy surface, whereas structure 1(c) represents the transition-state for nitrous oxide dissociation. At each point along the reaction coordinate, the sextet (total spin 5/2) potential energy surface lies below those of the doublet (total spin 1/2) and quartet (total spin 3/2) for Fe. In the case of $\mathrm{Co}$, the lowest energy is for the quintet (total spin 2). For this reason, we report results only for the sextet spin-state in the case of Fe and for the quintet spin state for Co.

The energy of nitrous oxide adsorption, $\Delta \mathrm{E}_{\mathrm{ads}}$, is defined as the difference in energy between structures 1(a) and 1(b). For Fe-ZSM-5 this value is $-6.6 \mathrm{kcal} / \mathrm{mol}$ and the corresponding value of the enthalpy of adsorption, $\Delta \mathrm{H}_{\mathrm{ads}}$, is $-7.2 \mathrm{kcal} / \mathrm{mol}$ at $298 \mathrm{~K}$. The calculated value of $\Delta \mathrm{H}_{\text {ads }}$ is smaller than that measured experimentally by Wood et al., $\Delta \mathrm{H}_{\mathrm{ads}}=-15 \mathrm{kcal} / \mathrm{mol}^{33}$ Failure to achieve agreement is perhaps not surprising, since the accuracy of DFT is particularly poor for weakly adsorbing species. ${ }^{34}$ For Co-ZSM-5, the values of $\Delta \mathrm{E}_{\mathrm{ads}}$ and $\Delta \mathrm{H}_{\mathrm{ads}}$ are $-5.2 \mathrm{kcal} / \mathrm{mol}$ and $-5.8 \mathrm{kcal} / \mathrm{mol}$, respectively.

The calculated frequency shifts for $\mathrm{N}_{2} \mathrm{O}$ adsorbed on $\mathrm{Z}^{-}[\mathrm{FeO}]^{+}$and $\mathrm{Z}^{-}[\mathrm{CoO}]^{+}$are presented in Table 1. Results are given for adsorption through both the oxygen and the nitrogen end of the molecule. Our calculations show a red-shift of the symmetric mode and a blue-shift of the asymmetric mode of $\mathrm{N}_{2} \mathrm{O}$ with respect to gas-phase molecule when $\mathrm{N}_{2} \mathrm{O}$ is adsorbed through the oxygen end of the molecule. Similar calculations for nitrous oxide adsorbed through the nitrogen end of the molecule show a blue shift for both modes. These trends are identical for Fe- and Co-ZSM-5 and are consistent with 
previous theoretical calculations of the interactions of $\mathrm{N}_{2} \mathrm{O}$ with other cations. ${ }^{35}$ Recently reported infrared spectra of $\mathrm{N}_{2} \mathrm{O}$ adsorbed on Fe-ZSM-5 at $298 \mathrm{~K}$ indicate a red shift for both vibrational modes of $\mathrm{N}_{2} \mathrm{O}$, suggesting a preference for adsorption through the nitrogen end of the molecule. ${ }^{33}$

The activation energy for nitrous oxide dissociation, $E_{\text {act, }}$ is defined as the difference in energy between the adsorbed structure 1(b) and the transition-state 1(c). This value, corrected for zero-point energy, is $37.6 \mathrm{kcal} / \mathrm{mol}$ for Fe-ZSM-5. The imaginary frequency associated with the transition-state is $726 i \mathrm{~cm}^{-1}$. The major difference between the transition state and the adsorbed structure is the bending of the N$\mathrm{N}^{\prime}-\mathrm{O}^{\prime \prime}$ bond angle from $180^{\circ}$ in the adsorbed state to $150.6^{\circ}$ at the transition-state. The activation energy for nitrous oxide dissociation, corrected for zero-point energy, is 32.9 $\mathrm{kcal} / \mathrm{mol}$ for Co-ZSM-5. The imaginary frequency associated with the transition-state is $756 i \mathrm{~cm}^{-1}$. Here too, the major difference between the transition state and the adsorbed state is the bending of the $\mathrm{N}-\mathrm{N}^{\prime}-\mathrm{O}^{\prime \prime}$ bond angle from $180^{\circ}$ in the adsorbed state to $151.3^{\circ}$ in the transition-state.

The product of Reaction 2 is $\mathrm{Z}^{-}\left[\mathrm{MO}_{2}\right]^{+}$. The calculated distance between the two $\mathrm{O}$ atoms is $0.137 \mathrm{~nm}$ in the case of $\mathrm{Fe}$ and $0.133 \mathrm{~nm}$ in the case of Co. The corresponding $\mathrm{M}-\mathrm{O}$ bond distances are 0.175 and $0.177 \mathrm{~nm}$ for Fe and 0.186 and 0.170 $\mathrm{nm}$ for Co. Spectroscopic observations made on Fe-ZSM-5 confirm the presence of a stable form of diatomic oxygen associated with Fe. Based on ESR studies of Fe-ZSM-5 $(\mathrm{Si} / \mathrm{Al}=14, \mathrm{Fe} / \mathrm{Al}=1), \mathrm{Chen}$ et al. suggest the presence of superoxide ions, $\mathrm{O}_{2}{ }^{-}$, at $77 \mathrm{~K}^{36}$ Diatomic oxygen surface species have also been observed in Fe-ZSM-5 by Gao et al. using in situ UV-Raman spectroscopy. ${ }^{37}$ In the presence of gas-phase $\mathrm{O}_{2}$, Gao et al. 
observe a distinct band at $730 \mathrm{~cm}^{-1}$, which they assign to a peroxide anion, $\mathrm{O}_{2}^{2-}$. The band disappears upon purging with He, but reappears after subsequent exposure to $\mathrm{O}_{2}$. The band vanishes at $540 \mathrm{~K}$, indicating weak adsorption to the surface.

The calculated vibrational modes associated with $\mathrm{O}_{2}$ in $\mathrm{Z}\left[\mathrm{Fe}(\mathrm{O})_{2}\right]^{+}$are 501, 652, and $986 \mathrm{~cm}^{-1}$. We attribute the frequencies at 501 and $652 \mathrm{~cm}^{-1}$ to the bending modes of $\left[\mathrm{Fe}-(\mathrm{O})_{2}\right]^{+}$. These modes are similar to those observed for ferrous cytochrome P450cam, which occur at 402 and $540 \mathrm{~cm}^{-1}$ reported by MacDonald et al. ${ }^{38}$ As noted above, Gao et al. [35] have observed a band at $730 \mathrm{~cm}^{-1}$ for adsorbed $\mathrm{O}_{2}$ but do not assign this band to a specific mode. The vibrational frequency at $986 \mathrm{~cm}^{-1}$ is assigned to vibrations of the O-O bond and lies in a range characteristic of both peroxide and superoxide species. Peroxides on various metal oxides exhibit bands in the region of $640-970 \mathrm{~cm}^{-1}$, whereas superoxide complexes exhibit bands in the range of $1015-1180 \mathrm{~cm}^{-1} \cdot 39,40$ The observed frequency of for O-O vibrations in cytochrome $\mathrm{P} 450$ cam is $1139 \mathrm{~cm}^{-1} .38$

The possibility that $\mathrm{O}_{2}$ desorption could occur via the process

$$
\mathrm{Z}^{-}\left[\mathrm{MO}_{2}\right]^{+} \rightarrow \mathrm{Z}^{-}[\mathrm{M}]^{+}+\mathrm{O}_{2}(\mathrm{~g})
$$

was considered. Since our model is based on an isolated cationic site, the occurrence of Reaction 2a would require the metal cation to adopt a formal charge of +1 . As noted in the Introduction, this state of Fe or Co seems unlikely, since ESR studies by Kucherov et al. on Fe-ZSM-5 and magnetic susceptibility studies by Armor et al. on Co-ZM-5 show no evidence for $\mathrm{Fe}^{+}$or $\mathrm{Co}^{+} ., 19$ Our calculations of the energetics for Reaction 2a further support the unlikelihood of the occurrence of this process. The calculated values of for the heat of energy change upon desoprtion, $\Delta \mathrm{E}_{\text {des }}$, are 94.9 and $85.6 \mathrm{kcal} / \mathrm{mol}$ for $\mathrm{Fe}$ and Co, respectively. This energetic penalty is compensated by an entropic gain of 
approximately of $\mathrm{T} \Delta \mathrm{S}^{0}=+25 \mathrm{kcal} / \mathrm{mol}$ at $723 \mathrm{~K}$, but even so the overall energetics for Reaction $2 \mathrm{a}$ are prohibitive.

Figures 3 and 4 show the reaction profiles for Reactions 3 and 4 occurring on FeZSM-5 and Co-ZSM-5, respectively. The energy of nitrous oxide adsorption, $\Delta \mathrm{E}_{\mathrm{ads}}$, is 4.9 and $-5.2 \mathrm{kcal} \cdot \mathrm{mol}^{-1}$ for Fe-ZSM-5 and Co-ZSM-5, respectively. The corresponding values of enthalpy of adsorption, $\Delta \mathrm{H}_{\mathrm{ads}}$, are -5.5 and $-5.8 \mathrm{kcal} \cdot \mathrm{mol}^{-1}$ at $298 \mathrm{~K}$. These values are comparable to those reported for Reaction 1 . The activation energy for $\mathrm{N}_{2} \mathrm{O}$ dissociation, $\mathrm{E}_{\text {act, }}$ corrected for zero-point energy, is $44.6 \mathrm{kcal} / \mathrm{mol}$ for Fe-ZSM-5 and $40.2 \mathrm{kcal} / \mathrm{mol}$ for Co-ZSM-5.

The desorption of $\mathrm{O}_{2}$ from $\mathrm{Z}\left[\mathrm{MO}\left(\mathrm{O}_{2}\right)\right]^{+}$occurs via Reaction 5. The energy of reaction for this process of is $51.9 \mathrm{kcal} / \mathrm{mol}$ for $\mathrm{Z}\left[\mathrm{FeO}\left(\mathrm{O}_{2}\right)\right]^{+}$and $52.8 \mathrm{kcal} / \mathrm{mol}$ for $\mathrm{Z}^{-}$ $\left[\mathrm{CoO}\left(\mathrm{O}_{2}\right)\right]^{+}$- roughly half that computed for Reaction 2a. When one takes in to account the entropy gained upon the desorption of $\mathrm{O}_{2}$, the contribution of entropy to the free energy of desorption is $\mathrm{T} \Delta \mathrm{S}^{0}=+25 \mathrm{kcal} / \mathrm{mol}$ at $723 \mathrm{~K}$. As a consequence, the free energy change for Reaction 5 lies in a range, which makes it a plausible candidate for the release of $\mathrm{O}_{2}$.

In the preceding discussion a valence of -1 has been assigned to the zeolite framework and a valence of +1 to the charge-compensating group, e.g., $[\mathrm{FeO}]^{+},\left[\mathrm{FeO}_{2}\right]^{+}$. Such use of valence is merely a convenience, since it is known that zeolites are soft bases and that covalent as well as ionic bonding is involved in the binding of the chargecompensating cation. For example, when protons are the charge-compensating cation, the charge on the Brønsted acid proton has been estimated to be +0.3 , rather than +1 . In the present study, we have performed a Mulliken Population Analysis for the structures 
given in Figures 1(a), 1(d), and 3(a). ${ }^{41}$ The Mulliken Charges associated with $\left[\mathrm{FeO}_{\mathrm{X}}\right]$ are $+0.27,+0.29$, and +0.22 for $\mathrm{x}=1,2$, and 3 , respectively. The corresponding charges on Fe were computed to be $+0.68,+0.75$, and +0.98 for $x=1,2$, and 3 , respectively. These results indicate that the charge on $\mathrm{Fe}$ increases with increasing number of $\mathrm{O}$ ligands, but does not reach or exceed the maximum valence of $\mathrm{Fe},+3$.

The apparent rate coefficient for nitrous oxide dissociation can be determined from the sequence of Reactions 1-5. The overall rate of $\mathrm{N}_{2} \mathrm{O}$ dissociation is given by the sum of the rates of Reactions 2 and 4 :

$$
-\mathrm{r}_{\mathrm{N} 2 \mathrm{O}}=\mathrm{r}_{\mathrm{N} 2}=\mathrm{k}_{2}\left[\mathrm{Z}[\mathrm{MO}]^{+}\left(\mathrm{N}_{2} \mathrm{O}\right)\right]+\mathrm{k}_{4}\left[\mathrm{Z}^{-}\left[\mathrm{MO}_{2}\right]^{+}\left(\mathrm{N}_{2} \mathrm{O}\right)\right]
$$

If we assume steps 1 and 3 are quasi-equilibrated because of the weak binding of $\mathrm{N}_{2} \mathrm{O}$, we can write:

$$
\begin{gathered}
{\left[\mathrm{Z}^{-}[\mathrm{MO}]^{+}\left(\mathrm{N}_{2} \mathrm{O}\right)\right]=\mathrm{K}_{1}\left[\mathrm{~N}_{2} \mathrm{O}\right]\left[\mathrm{Z}^{-}[\mathrm{MO}]^{+}\right]} \\
{\left[\mathrm{Z}^{-}\left[\mathrm{MO}_{2}\right]^{+}\left(\mathrm{N}_{2} \mathrm{O}\right)\right]=\mathrm{K}_{3}\left[\mathrm{Z}^{-}\left[\mathrm{MO}_{2}\right]^{+}\right]\left[\mathrm{N}_{2} \mathrm{O}\right]} \\
\mathrm{r}_{\mathrm{N} 2}=\mathrm{k}_{2} \mathrm{~K}_{1}\left[\mathrm{Z}^{-}[\mathrm{MO}]^{+}\right]\left[\mathrm{N}_{2} \mathrm{O}\right]+\mathrm{k}_{4} \mathrm{~K}_{3}\left[\mathrm{Z}^{-}\left[\mathrm{MO}_{2}\right]^{+}\right]\left[\mathrm{N}_{2} \mathrm{O}\right]
\end{gathered}
$$

The site balance on the active centers is given by:

$$
\left[\mathrm{Z}[\mathrm{MO}]^{+}\right]_{0}=\left[\mathrm{Z}[\mathrm{MO}]^{+}\right]+\left[\mathrm{Z}^{-}\left[\mathrm{MO}_{2}\right]^{+}\right]+\left[\mathrm{Z}\left[\mathrm{MO}\left(\mathrm{O}_{2}\right)\right]^{+}\right]
$$

If we assume that $\mathrm{Z}[\mathrm{MO}]^{+}$and $\mathrm{Z}\left[\mathrm{MO}_{2}\right]^{+}$are the most abundant surface species, the site balance can be rewritten in terms of surface coverage:

$$
1=\theta_{\mathrm{MO}}+\theta_{\mathrm{MO} 2}
$$

where $\theta_{\mathrm{MO}}=\left[\mathrm{Z}^{-}[\mathrm{MO}]^{+}\right] /\left[\mathrm{Z}[\mathrm{MO}]^{+}\right]_{0}$ and $\theta_{\mathrm{MO} 2}=\left[\mathrm{Z}^{-}\left[\mathrm{MO}_{2}\right]^{+}\right] /\left[\mathrm{Z}^{-}[\mathrm{MO}]^{+}\right]_{0}$. Since Reaction 4 has the higher activation energy, we assume that it is rate-limiting:

$$
\begin{aligned}
\mathrm{r}_{2} & =\mathrm{r}_{4} \\
\mathrm{k}_{2}\left[\mathrm{Z}^{-}[\mathrm{MO}]^{+}\left(\mathrm{N}_{2} \mathrm{O}\right)\right] & =\mathrm{k}_{4}\left[\mathrm{Z}^{-}\left[\mathrm{MO}_{2}\right]^{+}\left(\mathrm{N}_{2} \mathrm{O}\right)\right]
\end{aligned}
$$




$$
\mathrm{k}_{2} \mathrm{~K}_{1}\left[\mathrm{Z}^{-}[\mathrm{MO}]^{+}\right]=\mathrm{k}_{4} \mathrm{~K}_{3}\left[\mathrm{Z}^{-}\left[\mathrm{MO}_{2}\right]^{+}\right]
$$

Rewriting our expression in terms of the surface coverage:

$$
\begin{gathered}
\mathrm{k}_{2} \mathrm{~K}_{1} \theta_{\mathrm{MO}}=\mathrm{k}_{4} \mathrm{~K}_{3}\left(1-\theta_{\mathrm{MO}}\right) \\
\theta_{\mathrm{MO}}=\mathrm{K}^{\prime} /\left(1+\mathrm{K}^{\prime}\right)
\end{gathered}
$$

where $\mathrm{K}^{\prime}=\mathrm{k}_{4} \mathrm{~K}_{3} /\left(\mathrm{k}_{2} \mathrm{~K}_{1}\right)$. Since $\mathrm{E}_{A c t, 2}<\mathrm{E}_{A c t, 4}$ we assert that $\mathrm{k}_{2}>>\mathrm{k}_{4}$ and $\mathrm{K}_{3} \sim \mathrm{K}_{4}$. Hence, $\mathrm{K}^{\prime}<<1$ and

$$
\theta_{\mathrm{MO}}=0
$$

Thus, the overall rate of nitrous oxide dissociation could be written as:

$$
\begin{gathered}
-\mathrm{r}_{\mathrm{N} 2 \mathrm{O}}=2 \mathrm{k}_{4} \mathrm{~K}_{3}\left[\mathrm{Z}^{-}\left[\mathrm{MO}_{2}\right]^{+}\right]\left[\mathrm{N}_{2} \mathrm{O}\right] \\
-\mathrm{r}_{\mathrm{N} 2 \mathrm{O}}=\mathrm{k}_{\mathrm{app}}\left[\mathrm{N}_{2} \mathrm{O}\right]
\end{gathered}
$$

where $\mathrm{k}_{\mathrm{app}}=2 \mathrm{k}_{4} \mathrm{~K}_{3}\left[\mathrm{Z}^{-}\left[\mathrm{MO}_{2}\right]^{+}\right]$. The form of this rate expression is in good agreement with that found experimentally for Fe-ZSM-5. ${ }^{33}$

Based on the proposed mechanism, the experimental result that can be compared to the apparent activation energy, $\mathrm{E}_{\mathrm{app}}$, defined in two limiting cases:

$$
\begin{aligned}
& \mathrm{E}_{\mathrm{app}}=\mathrm{E}_{2}+\Delta \mathrm{H}_{1}, \text { if } \theta_{\mathrm{MO}} \sim 1 \\
& \mathrm{E}_{\mathrm{app}}=\mathrm{E}_{4}+\Delta \mathrm{H}_{3}, \text { if } \theta_{\mathrm{MO}} \sim 0
\end{aligned}
$$

Given the very high heat of desorption for $\mathrm{O}_{2}$ from $\mathrm{Z}\left[\mathrm{Fe}(\mathrm{O})_{2}\right]^{+}$, it can reasonably be assumed that $\theta_{\mathrm{MO}}=0$. From these considerations, $\mathrm{E}_{\mathrm{app}}=39.4 \mathrm{kcal} / \mathrm{mol}$ for Fe-ZSM-5 and $\mathrm{E}_{\mathrm{app}}=34.6 \mathrm{kcal} / \mathrm{mol}$.

Table 2 compares the calculated value of the apparent activation energy for $\mathrm{N}_{2} \mathrm{O}$ decomposition over Fe-ZSM-5 with those measured experimentally. Very good agreement is observed with the values of $E_{\text {app }}$ reported recently by Wood et al. ${ }^{33}$ The 
values of $\mathrm{E}_{\mathrm{app}}$ reported by Panov and coworkers are somewhat lower. ${ }^{5}$ In the case of CoZSM-5, the calculated value of $\mathrm{E}_{\text {app }}$ is significantly higher than the value of $26.4 \mathrm{kcal} / \mathrm{mol}$ reported experimentally by Kapteijn et al. ${ }^{1}$ However, in agreement with experimental observation the apparent activation energy is lower for Co-ZSM-5 than for Fe-ZSM-5.

The magnitude of the preexponential factor for the decomposition of $\mathrm{N}_{2} \mathrm{O}$ was estimated, assuming that the transition state for Reaction 4 involves a species that is mobile in two dimensions and has one degree of rotational freedom. ${ }^{42}$ For this calculation the concentration of Fe atoms on the surface of the zeolite pores is estimated in the following manner. The area occupied by an $\mathrm{O}$ atom in the pore is taken as 0.04 $\mathrm{nm}^{2}$, which leads to an $\mathrm{O}$-atom concentration of $2.5 \times 10^{15} \mathrm{O} / \mathrm{cm}^{2}$. The ratio of $\mathrm{Fe}$ to $\mathrm{O}$ can be determined from the values of the ratios of $\mathrm{Si} / \mathrm{Al}, \mathrm{O} / \mathrm{Si}$, and $\mathrm{Fe} / \mathrm{Al}$, which are taken to be 25,2 , and $0.1-0.5$, respectively. Thus, $\mathrm{Fe} / \mathrm{O}$ is $2 \times 10^{-3}-10^{-2}$ and the surface concentration of active sites is $5 \times 10^{12}-2.5 \times 10^{13} \mathrm{Fe} / \mathrm{cm}^{2}$. The contributions of vibrations to the partition functions in the reactant and transition states for Reaction 4 were determined from our quantum calculations. As seen in Table 2, the apparent first-order rate coefficient is estimated to be $4 \times 10^{7} \mathrm{~s}^{-1} \mathrm{~Pa}^{-1}$ for an assumed Fe/Al ratio of 0.5 . Similar calculations for Co-ZSM-5 give a value of $7 \times 10^{7} \mathrm{~s}^{-1} \mathrm{~Pa}^{-1}$. Variations in the computed modes between Fe- and Co-ZSM-5 account for the difference in the two values. Table 2 also shows that the preexponential factor calculated for Fe-ZSM-5 is one to two orders of magnitude smaller than that determined from experimentally.

Based upon the results presented in Table 2, the activity of Co-ZSM-5 is expected to be higher than that of Fe-ZSM-5 because the preexponential factor for Co-ZSM-5 is higher and the activation factor for this catalyst is lower. At a temperature of $723 \mathrm{~K}$, 
which is typical of $\mathrm{N}_{2} \mathrm{O}$ decomposition over both catalysts, the ratio of activities predicted is 33. This figure can be compared with the experimentally observed value of $88 .^{4}$

\section{Conclusions}

An analysis of the reaction pathway for $\mathrm{N}_{2} \mathrm{O}$ decomposition on Fe-ZSM-5 and Co-ZSM-5 suggests that metal oxo cations $\left([\mathrm{FeO}]^{+}\right.$and $\left.[\mathrm{CoO}]^{+}\right)$can serve as active centers. For both metals, the active center is transformed into $\left[\mathrm{MO}_{2}\right]^{+}$, a species that has characteristics intermediate between those of a metal superoxo and peroxo species. The apparent activation energy for $\mathrm{N}_{2} \mathrm{O}$ decomposition is calculated to be $39.4 \mathrm{kcal} / \mathrm{mol}$ for Fe-ZSM-5, which agrees well with experimental measurements. The apparent activation energy for Co-ZSM-5 is $34.6 \mathrm{kcal} / \mathrm{mol}$. This figure is higher than that reported experimentally. The preexponential factor for the apparent first-order rate coefficient for $\mathrm{N}_{2} \mathrm{O}$ decomposition is estimated to be $4 \times 10^{7} \mathrm{~s}^{-1} \mathrm{~Pa}^{-1}$ for Fe-ZSM-5 and $7 \times 10^{7} \mathrm{~s}^{-1} \mathrm{~Pa}^{-1}$ for Co-ZSM-5. In both cases $\mathrm{M} / \mathrm{Al}=0.5$. Consistent with experimental observation, the rate of $\mathrm{N}_{2} \mathrm{O}$ decomposition is predicted to be more rapid on Co-ZSM-5 than Fe-ZSM-5. This conclusion is a direct consequence of the lower activation energy and higher preexponential factor for $\mathrm{N}_{2} \mathrm{O}$ decomposition over Co-ZSM-5.

\section{Acknowledgments}

This work was supported by the Director, Office of Basic Energy Sciences, Chemical Sciences Division of the U.S. Department of Energy under contract number

DE-AC03-SF763098. J. A. R. acknowledges support provided by a graduate research 
fellowship from the National Science Foundation. Computational resources were

provided by the National Energy Resource Supercomputer Center (NERSC).

\section{References}

1. Kapteijn, F.; Rodreiguez-Mirasol, J.; Moulijn, J. A.; App. Catal. B 1996, 9, 25.

2. Li, Y.; Armor, J. N.; App. Catal. B 1992, 1, L21.

3. Chang, Y.-.F.; McCarty, J. G.; Wachsman, E. D.; Wong, V. L.; Appl. Catal. B 1994, 4, 283.

4. Li, Y.; Armor, J. N.; App. Catal. B 1994, 4, L11.

5. Panov, G. I.; Sobolev, V. I.; Kharitonov, A. S.; J. Mol. Catal. 1990, 61, 85.

6. da Cruz, R. S.; Mascarenhas, A. J. S.; Andrade, H. M. C.; App. Catal. B 1998, 18, 223.

7. Chang, Y.-.F.; McCarty, J. G.; Zhang, Y. L.; Catal. Lett. 1995, 38, 163.

8. Leglise, J.; Peunchi, J. O.; Hall, W. K.; J. Catal. 1984, 86, 392.

9. Lobree, L. J.; Hwang, I.; Reimer, J. A.; Bell, A. T.; J. Catal. 1999, 186, 242-253.

10. Voskoboinikov, T. V.; Chen. H. Y.; Sachtler, W. M. H.; J. Mol. Catal. 2000, 155, 155.

11. Marturano, P.; Drozdová, L.; Kogelbauer, A.; Prins, R.; J. Catal. 2000, 192, 236.

12. Battiston, A. A.; Bitter, J. H.; Koningsberger, D. C.; Catal. Lett. 2000, 66, 75.

13. Joyner, R.; Stockenhuber, M.; J. Phys. Chem. B 1999, 103, 5963.

14. Lewis, D. W.; Catlow, R. A.; Sankar, G.; J. Phys. Chem. 1995, 99, 2377.

15. Feng, X.; Hall, W. K.; Catal. Lett. 1997, 46, 11.

16. Rice, M. J.; Chakraborty, A. K.; Bell, A. T.; J. Catal. 1999, 186, 222.

17. Goodman, B. R.; Schneider, W. F.; Hass, K. C.; Adams, J. B.; J. Catal. 1998, 56, 183.

18. Goodman, B. R.; Hass, K. C.; Schneider, W. F.; Adams, J. B.; Catal. Lett. 1999, 103, 10452.

19. Kucherov, A. V.; Shelef, M.; J. Catal. 2000, 195, 106-112.

20. Drozdová, L; Maturano, P; WIchterlová, B; Kogelburger, A.; Prins, R. in Catalysis by Unique Metal Ion Structures in Solid Matrices, Eds. Centi, G; Wichterlova, B; Bell, A. T., Kluwer, Amsterdam, 2001. pp 85-94.

21. Yoshizawa, K.; Yumura, T.; Shiota, Y.; Yamabe, T.; Bull. Chem. Soc. Jpn. 2000, 73, 29.

22. Yoshizawa, K.; Yumura, T.; Shiota, Y.; Yamabe, T.; J. Phys. Chem. B 2000, 104, 734.

23. Yakovlev, A. L.; Zhidomirov, G. M.; van Santen, R. A.; Catal. Lett. 2001, 75, 45.

24. Yakovlev, A. L.; Zhidomirov, G. M.; van Santen, R. A.; J. Phys. Chem. B 2001, 105, 12297.

25. Olson, D. H.; Kokotallo, G.T.; Lawton, S. L.; Meier, W. M.; J. Phys. Chem. 1981, 85, 2238.

26. Parr, R. G.; Yang, W.; Oxford University Press: Oxford, 1989.

27. Becke, A. D.; Phys. Rev. A 1988, 38, 3098.

28. Lee, C.; Yang, W.; Parr, R.G.; Phys. Rev. B 1988, 37, 785.

29. Dolg, M.; Wedig, U.; Stoll, H.; Preuss, H.; J. Chem. Phys. 1987, 86, 866. 
30. Jaguar 4.0, Schrödinger, Inc., Portland, OR, 2000.

31. Gaussian 98, Gaussian In., Pittsburgh, PA, 1998.

32. McQuarrie, D. A.; Statistical Mechanics, HarperCollins Publisher Inc.: New York, 1973.

33. Wood, B. R.; Reimer, J. A.; Bell, A. T.; J. Catal. 2002, accepted.

34. Bates, S. P.; Van Santen, R. A.; Adv. Catal. 1998, 42, 1.

35. Borello, E.; Cerruti, L.; Ghiotti, G.; Guglielminotti, E.; Inorg. Chim. Acta 1972, 6, 45.

36. Chen, H.-Y.; El-Malki, El-M.; Wang, X.; van Santen, R. A.; Sachtler, W. M. H.; J. Mol. Catal. 2000, 162, 159.

37. Gao, Z.-X.; Kim, H.-S.; Sun, Q.; Sachtler, W. M. H.; Stair, P. C.; J. Phys. Chem. (in press).

38. Macdonald, I. D. G.; Sligar, S. G.; Christian, J. F.; Unno, M.; Champion, P. M.; J. Am. Chem. Soc. 1999, 121, 376.

39. Che, M.; Tench, A. J.; Adv. Catal. 1983, 32, 1.

40. Hu, S.; Schneider, A. J.; Kincaid, J. R.; J. Am. Chem. Soc. 1991, 113, 4815.

41. Mulliken, R. S.; J. Chem. Phys. 1962, 36, 3428.

42. Laidler, K. J.; Chemical Kinetics, Addison-Wesley Publishing Co.: Boston, 1987. 


\section{Figure Captions}

Figure 1. Energy versus reaction coordinate for first nitrous oxide decomposition over $Z^{-}$ $[\mathrm{FeO}]^{+}$

Figure 2. Energy verus reaction coordinate for first nitrous oxide decomposition over $Z^{-}$ $[\mathrm{CoO}]^{+}$

Figure 3. Energy versus reaction coordinate for first nitrous oxide decomposition over $\mathrm{Z}^{-}$ $\left[\mathrm{FeO}_{2}\right]^{+}$

Figure 4. Energy versus reaction coordinate for first nitrous oxide decomposition over $\mathrm{Z}^{-}$ $\left[\mathrm{CoO}_{2}\right]^{+}$ 
Table 1. Computed frequency shifts for $\mathrm{N}_{2} \mathrm{O}$ adsorbed on $\mathrm{Z}^{-}[\mathrm{MO}]^{+}$

\begin{tabular}{|c|c|c|c|c|}
\hline Mode $^{(a)}$ & $\mathrm{Z}^{-}[\mathrm{FeO}]^{+}(\mathrm{ONN})$ & $\mathrm{Z}^{-}[\mathrm{FeO}]^{+}(\mathrm{NNO})$ & $\mathrm{Z}^{-}[\mathrm{CoO}]^{+}(\mathrm{ONN})$ & $\mathrm{Z}^{-}[\mathrm{CoO}]^{+}(\mathrm{NNO})$ \\
\hline$\Delta v(\mathrm{~N}-\mathrm{N})\left(\mathrm{cm}^{-1}\right)$ & 15 & 48 & 15 & 39 \\
\hline$\Delta v(\mathrm{O}-\mathrm{O})\left(\mathrm{cm}^{-1}\right)$ & -47 & 45 & -19 & 46 \\
\hline
\end{tabular}

(a) Calculated frequency shift relative to gas-phase $\mathrm{N}_{2} \mathrm{O}$. 
Table 2. Calculated rate parameters for $\mathrm{N}_{2} \mathrm{O}$ dissociation over M-ZSM-5

\begin{tabular}{|c|c|c|c|c|}
\hline Sample [Ref.] & $\mathrm{Fe} / \mathrm{Al}(\mathrm{Si} / \mathrm{Al})$ & Fe wt. $\%$ & $\mathrm{E}_{\mathrm{app}}, \mathrm{kcal} / \mathrm{mol}$ & $\mathrm{k}_{0}, \mathrm{~s}^{-1}\left(\mathrm{~Pa} \mathrm{~N}_{2} \mathrm{O}\right)^{-1}$ \\
\hline Fe-ZSM-5 & & & 39.4 & $4 \times 10^{7}$ \\
\hline Co-ZSM-5 & & & 34.6 & $7 \times 10^{7}$ \\
\hline Fe-ZSM-5 [32] & $0.01(25)$ & 0.17 & 42.4 & $8.1 \times 10^{7}$ \\
\hline Fe-ZSM-5 [32] & $0.17(25)$ & 0.57 & 42.1 & $1.8 \times 10^{8}$ \\
\hline Fe-ZSM-5 [32] & $0.33(25)$ & 1.11 & 42.3 & $3.0 \times 10^{9}$ \\
\hline Fe-ZSM-5 [5] & $0.033(50)$ & 0.056 & $35 \pm 4$ & $3.1 \times 10^{7}$ \\
\hline Fe-ZSM-5 [5] & $0.21(50)$ & 0.35 & $37 \pm 1.5$ & $1.0 \times 10^{8}$ \\
\hline
\end{tabular}


Figure 1.

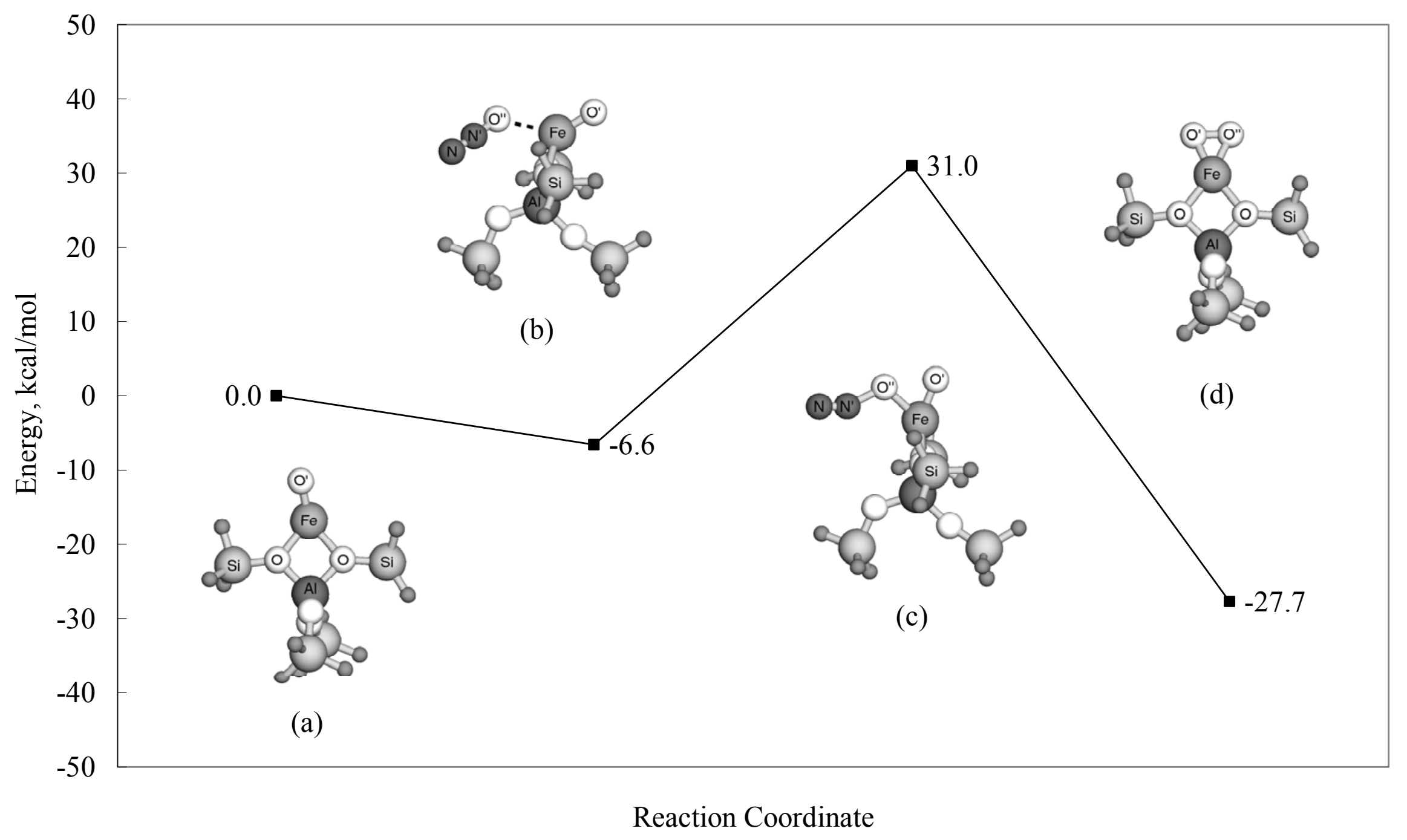


Figure 2.

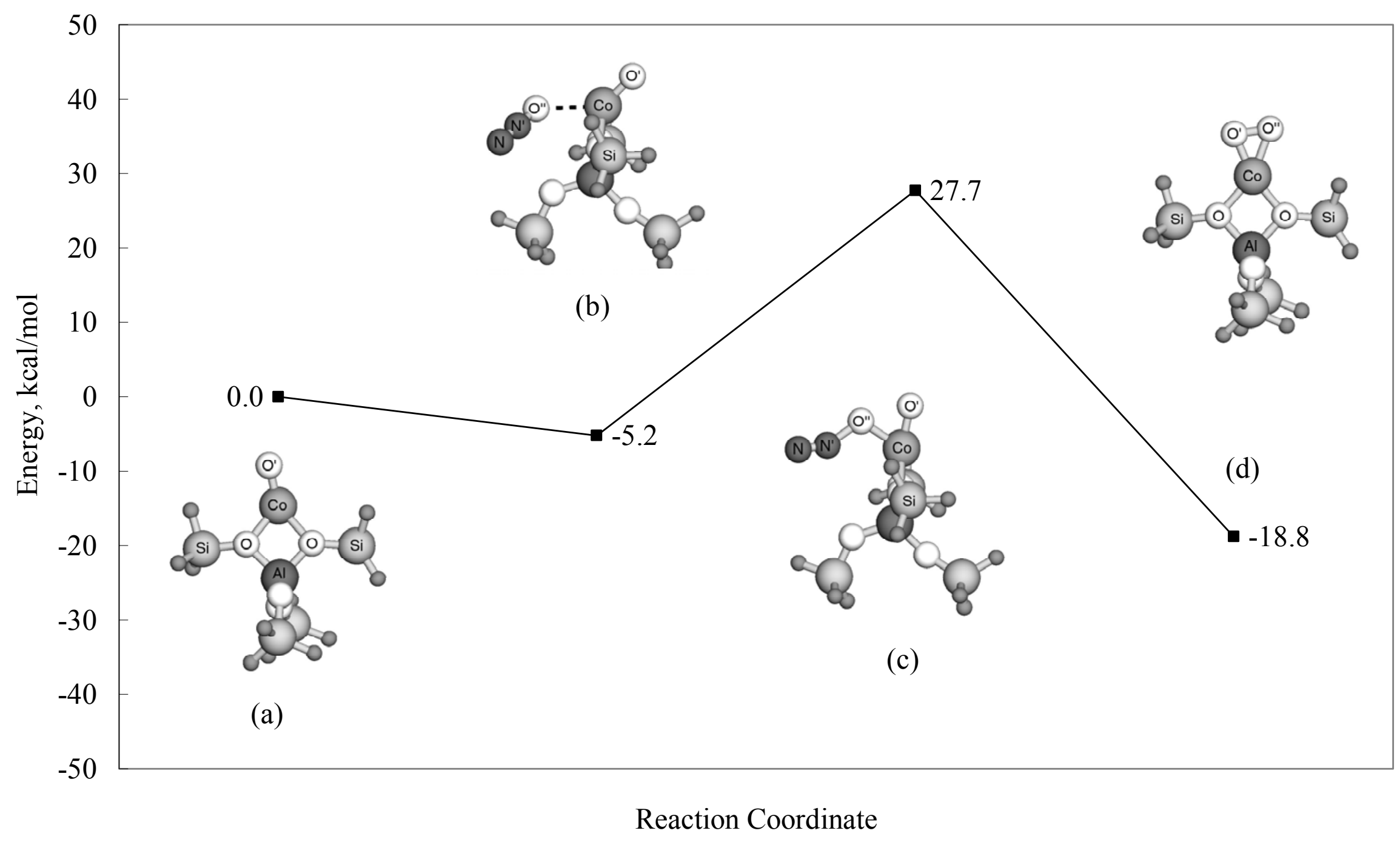


Figure 3.

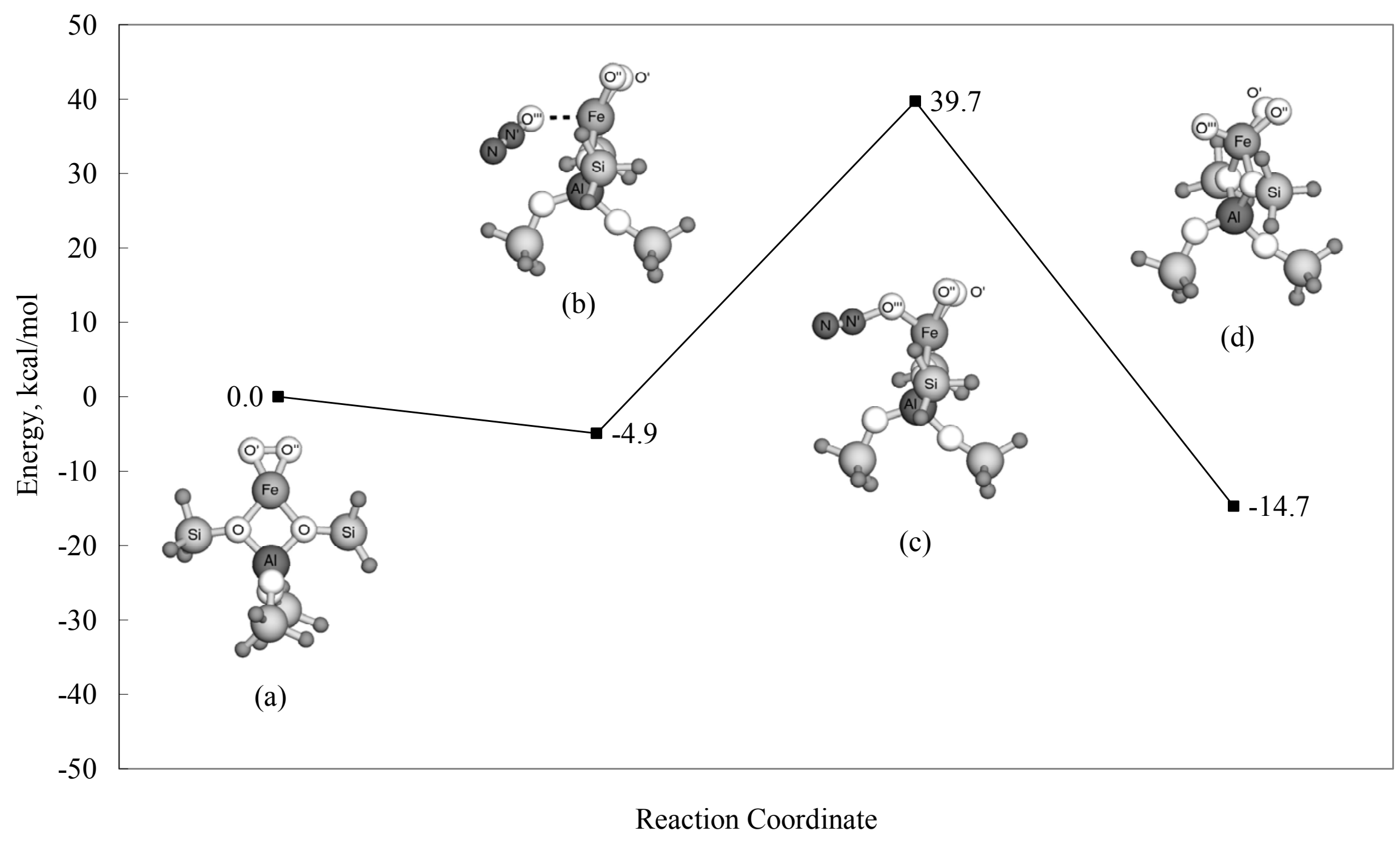


Figure 4.

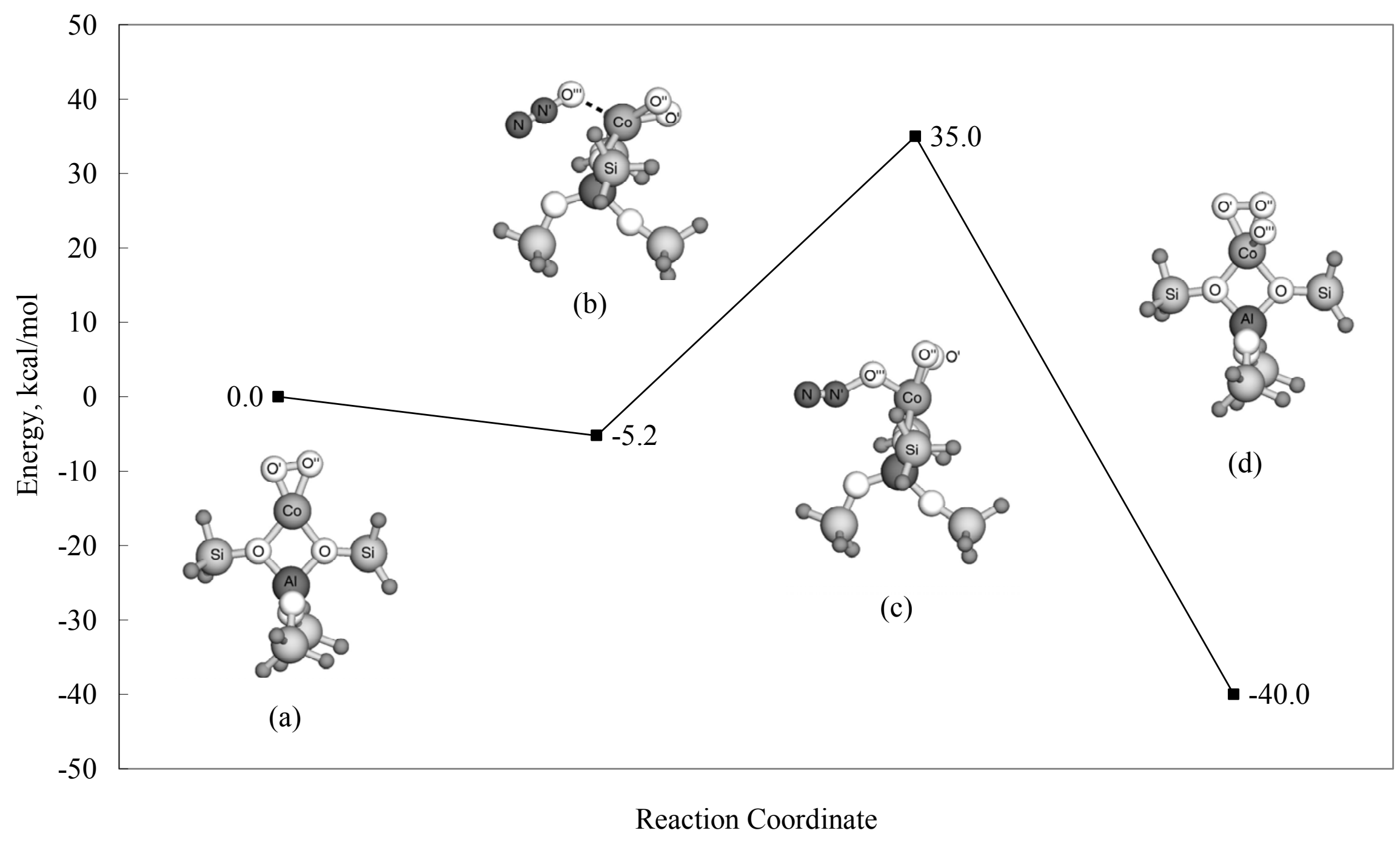

